David Shaw

\title{
Organ donation is the right decision: a delicate truth
}

Received: 28 April 2015

Accepted: 17 May 2015

Published online: 11 June 2015

(C) Springer-Verlag Berlin Heidelberg and ESICM 2015

The author is a member of the United Kingdom Donation Ethics Committee, but the views expressed in this paper are his own and do not represent those of the committee.

\section{Shaw (区)}

Institute for Biomedical Ethics, University of Basel,

Bernoullistrasse 28, 4056 Basel, Switzerland

e-mail: david.shaw@unibas.ch

Imagine that you're walking home past a pond one day when you see a toddler fall in ten feet away from you. The water is only one foot deep and there's no risk of you drowning. Should you save the child?

Most people would say "of course", and anyone who chose not to save a child in such a situation would be regarded as having made the wrong decision. Now imagine that you have an opportunity to save a child's life without even getting your trousers wet, and other people will benefit too. All you have to do is donate your organs after your death; on average this will save one life and improve several others. Should you do so? Some people would again say "of course", but many people choose not to do so. Curiously, however, those who choose not to donate their organs are unlikely to be subjected to the same type of criticism as those who do not choose to rescue drowning children. In fact, it is regarded as rather insensitive to claim that organ donation is "the right choice", or to imply that people who do not wish to donate their organs are acting wrongly. Why is this the case?

In large part, reluctance to criticise those who choose not to donate can be attributed to the fact that organ donation is regarded as a highly personal matter. Some organisations that might be expected to promote organ donation (including many governments) state officially that they adopt a neutral stance, which is somewhat curious given that neutrality is not required in terms of fighting infectious diseases or obesity or smoking, despite the personal nature of some of these topics. Even among those who are strongly in favour of organ donation, it can be regarded as offensive to claim that those who prevent donation are making "the wrong decision". (At a recent organ donation meeting, someone said that it was "disgusting" to make this claim.) The claim that donation is a good thing has even been used by those who oppose presumed consent systems as ammunition; a Swiss member of parliament objected that "they're basically saying that you're a bad person if you don't donate your organs".

Why is organ donation regarded as being a particularly personal matter? Essentially this is because of mortality. Most people will only have an opportunity to donate their organs once they are dead-and soon after they are dead. Decisions regarding donation are rightly regarded as being a matter for each individual person-it is a personal choice whether to donate your organs, and if you don't want to then that is up to you, just as it would be your choice not to save the drowning child. Because organs must be removed soon after death while families are still grieving, some people might want to donate their organs but worry that it would upset their families. Others might have personal objections to donation, or might believe that donation is against the tenets of a particular religion 
(though most major religions support donation). But saying that something is a matter of personal choice is quite different from saying that all such choices must be applauded, regardless of their consequences. It is true that people make whichever decision is right for themselves and their families, but that does not mean that the decision is objectively the right one, all things considered.

Failing to register as an organ donor means that, in the unlikely event that you die in a way that makes donation possible, you will be contributing to considerable preventable harm by denying recipients essential organs. Equally, every time a family refuses to authorise donation from a deceased relative, this is very likely to contribute to the avoidable death of one person and increased suffering of others. If people choose in advance not to donate their organs, that is up to them, but there is no reason to tiptoe around the truth regarding the consequences of an overruling family's actions-refusal must be informed, just like consent. It is rather ironic that it is death that renders organ donation decisions out of bounds, given that it is also death that means organ donation can take place at virtually zero cost to the donor. Indeed, it might be because there are very few times in one's life that one can save a life at virtually zero cost that people just aren't used to thinking about such situations.

Why do families sometimes overrule the decisions of registered organ donors? From their perspective, this is certainly understandable, as they are very upset (which is why they must be counselled very sensitively); however, evidence shows that many of them later come to see a 'veto' as the wrong decision. It is true that choosing to donate your organs might upset your family in the short term, but under which other circumstances would it be regarded as acceptable to spare your family some emotional suffering if the only way of doing so is to deny someone life-saving assistance? Here is another example to illustrate the point.

Imagine that you're walking to your father's funeral past a pond when you see a toddler fall in ten feet away from you. The water is only one foot deep and there's no risk of you drowning; however, it will upset your relatives that you miss your father's funeral or are late but very muddy, and they are of course already upset that he's dead, meaning you're making things worse. Should you save the child?

This example illustrates the great cost of allowing a preventable death to occur in order to spare your family's feelings. Why do people seem to believe that drowning children should be saved but those in need of organs should not? It appears likely that the phenomenon of moral distance is at play here: it is ethically easy to decide to save a child who is crying for help right in from of you, but harder to risk upsetting your family for the sake of someone you have not and will never meet. Those in need of organs are much less obviously in need than a drowning child right in front of you, and this less obvious need makes it seem more acceptable to choose not to donate your organs. But the need is no less great.

It is a delicate truth, but organ donation is the right decision. How else could you describe a decision that saves lives and prevents suffering at virtually zero cost? People might not like it when they're told that refusal to donate is the wrong decision, but there's no other way to characterise it. Everyone has a right to make their own decisions about donation, but no-one has a right not to be told that it's a bad one, all things considered.

Conflicts of interest No conflicts of interest to declare. 